\begin{tabular}{cc}
\hline International Journal of Advanced Astronomy, $8(1)(2020)$ & $19-26$ \\
SPC & International Journal of Advanced Astronomy \\
Website: www.sciencepubco.com/index.php/IJAA \\
Research paper
\end{tabular}

\title{
Effectiveness of KS elements in satellite orbit prediction using earth's gravity, drag and solar radiation pressure
}

\author{
T. R. Saritha Kumari ${ }^{1}$, M. Xavier James Raj ${ }^{1 *}$ \\ ${ }^{1}$ Applied Mathematics Division, Vikram Sarabhai Space Centre, Thiruvananthapuram-695022 \\ *Corresponding author E-mail: xavierjamesraj@gmail.com
}

\begin{abstract}
Satellite moving under the gravitational field of Earth deviates from its two-body elliptic orbit, due to the combined effects of the gravitational field of Earth, atmospheric drag, solar radiation pressure, third-body gravitational effects, etc. This paper utilizes the KS regular element equations to solve Newtonian equations of motion to obtain numerical solution with respect to perturbing forces, like, Earth's gravity (includes zonal, sectorial and tesseral harmonics terms), atmospheric drag and solar radiation pressure. Effectiveness of the theory is illustrated by comparing the results with some of the existing theories in literature.
\end{abstract}

Keywords: Orbit Prediction; Solar Radiation Pressure; Semi-Major Axis; KS Elements.

\section{Introduction}

The effect of various perturbing forces like the shape of the Earth, atmospheric drag, the Sun's radiation, attraction due to Sun and Moon, the Earth's magnetic field, etc. causes the geocentric space object to deviate from its two-body elliptic orbit. For near Earth's satellite orbit, the perturbations due to asphericity of the Earth and atmospheric drag plays a major role, but for high altitude orbits, solar radiation pressure is more important than atmospheric drag. Hence to predict the motion of the satellite precisely, a mathematical model for these forces must be selected properly for integrating the resulting differential equations of motion. The classical Newtonian equations of motion, which are nonlinear, are not suitable for long-term integration for computing accurate orbit.

The KS transformation by Kustaanheimo and Stiefel [1] is used to regularize the nonlinear Kepler equation of motion and reduced it into linear differential equations of a harmonic oscillator of constant frequency. The method of KS elements [2] has been found to be a very powerful method for obtaining numerical solution with respect to any type of perturbing forces, as the equations are less sensitive to round off and truncation errors [3]. The equations are everywhere regular comparing to the classical Newtonian equations, which are singular at the collision of two bodies.

In this paper a detailed study is carried out for orbit prediction using KS differential equations by including the non-spherical gravitational potential (zonal, sectorial and tesseral harmonic terms) of the Earth, atmospheric drag and solar radiation pressure as perturbing forces. Higher order Earth's gravity (zonal, sectorial and tesseral) terms are included by utilizing the recurrence relations of associated Legendre polynomial and its derivatives. To know the effectiveness of the theory, the results are compared with some of the existing theories in literature.

\section{Equations of motion}

The Newtonian equations of motion are given by,

$\ddot{\vec{x}}+\frac{K^{2}}{r^{3}} \vec{x}=\vec{P}-\frac{\partial V}{\partial x}, K^{2}=k^{2}(M+m)$,

where $\overrightarrow{\mathrm{x}}$ denotes the position vector of the particle with respect to a coordinate system centred at the mass $\mathrm{M}$ and perturbed by a perturbed force $\overrightarrow{\mathrm{P}}$ and a perturbing potential $V$, dot represent differentiation with respect to the time $t, r$ is the distance between the masses, $\mathrm{k}^{2}$ is the universal gravitational constant, and $\frac{\partial V}{\partial \vec{x}}$ is the gradient of the scalar function $V(\vec{x}, t)$.

KS element equations of motion [2], [4] are given by, 


$$
\begin{aligned}
& \frac{\mathrm{d} \omega}{\mathrm{dE}}=-\frac{\mathrm{r}}{8 \omega^{2}} \frac{\partial \mathrm{V}}{\partial \mathrm{t}}-\frac{1}{2 \omega}\left(\frac{\mathrm{d} \overrightarrow{\mathrm{u}}}{\mathrm{dE}}, \mathrm{L}^{\mathrm{T}} \overrightarrow{\mathrm{P}}\right) \\
& \frac{\mathrm{d} \vec{\alpha}}{\mathrm{dE}}=\left\{\frac{1}{2 \omega^{2}}\left[\frac{\mathrm{V}}{2} \overrightarrow{\mathrm{u}}+\frac{\mathrm{r}}{4}\left(\frac{\partial \mathrm{V}}{\partial \overrightarrow{\mathrm{u}}}-2 \mathrm{~L}^{\mathrm{T}} \overrightarrow{\mathrm{P}}\right)\right]+\frac{2}{\omega} \frac{\mathrm{d} \omega}{\mathrm{dE}} \frac{\mathrm{d} \overrightarrow{\mathrm{u}}}{\mathrm{dE}}\right\} \sin \frac{\mathrm{E}}{2} \\
& \frac{\mathrm{d} \vec{\beta}}{\mathrm{dE}}=\left\{\frac{-1}{2 \omega^{2}}\left[\frac{\mathrm{V}}{2} \overrightarrow{\mathrm{u}}+\frac{\mathrm{r}}{4}\left(\frac{\partial \mathrm{V}}{\partial \overrightarrow{\mathrm{u}}}-2 \mathrm{~L}^{\mathrm{T}} \overrightarrow{\mathrm{P}}\right)\right]+\frac{2}{\omega} \frac{\mathrm{d} \omega}{\mathrm{dE}} \frac{\mathrm{d} \overrightarrow{\mathrm{u}}}{\mathrm{dE}}\right\} \cos \frac{\mathrm{E}}{2} \\
& \frac{\mathrm{d} \tau}{\mathrm{dE}}=\frac{1}{8 \omega^{3}}\left(\mathrm{~K}^{2}-2 \mathrm{rV}\right)-\frac{\mathrm{r}}{16 \omega^{3}}\left(\overrightarrow{\mathrm{u}}, \frac{\partial \mathrm{V}}{\partial \overrightarrow{\mathrm{u}}}-2 \mathrm{~L}^{\mathrm{T}} \overrightarrow{\mathrm{P}}\right)-\frac{2}{\omega^{2}} \frac{\mathrm{d} \omega}{\mathrm{dE}}\left(\overrightarrow{\mathrm{u}}, \frac{\mathrm{d} \overrightarrow{\mathrm{u}}}{\mathrm{dE}}\right)
\end{aligned}
$$

with

$\overrightarrow{\mathrm{u}}=\vec{\alpha}(\mathrm{E}) \cos \frac{\mathrm{E}}{2}+\vec{\beta}(\mathrm{E}) \sin \frac{\mathrm{E}}{2}$,

$\frac{\mathrm{d} \overrightarrow{\mathrm{u}}}{\mathrm{dE}}=-\frac{1}{2} \vec{\alpha}(\mathrm{E}) \sin \frac{\mathrm{E}}{2}+\frac{1}{2} \vec{\beta}(\mathrm{E}) \cos \frac{\mathrm{E}}{2}$,

$\tau=\mathrm{t}+\frac{1}{2 \omega}\left(\overrightarrow{\mathrm{u}}, \overrightarrow{\mathrm{u}}^{*}\right)$

$2 \omega^{2}=\frac{K^{2}}{r}-\frac{1}{2}|\dot{\vec{x}}|^{2}-V$

where $\mathrm{E}, \omega, \mathrm{t}$ are, respectively, generalized eccentric anomaly, angular frequency and physical time.

The components of the position vector $\overrightarrow{\mathrm{x}}$ of the particle are computed as, $\overrightarrow{\mathrm{x}}=\mathrm{L}(\overrightarrow{\mathrm{u}}) \overrightarrow{\mathrm{u}}$,

where,

$L(\vec{u})=\left[\begin{array}{cccc}u_{1} & -u_{2} & -u_{3} & u_{4} \\ u_{2} & u_{1} & -u_{4} & -u_{3} \\ u_{3} & u_{4} & u_{1} & u_{2} \\ u_{4} & -u_{3} & u_{2} & -u_{1}\end{array}\right]$

The radial distance of the particle is computed as, $r=u_{1}{ }^{2}+u_{2}{ }^{2}+u_{3}{ }^{2}+u_{4}{ }^{2}=\sqrt{x_{1}{ }^{2}+x_{2}{ }^{2}+x_{3}{ }^{2}}$

Velocity vector of the particle are as follows:

$\dot{\mathrm{x}}_{1}=\frac{4 \omega}{\mathrm{r}}\left(\mathrm{u}_{1} \mathrm{u}_{1}{ }^{*}-\mathrm{u}_{2} \mathrm{u}_{2}{ }^{*}-\mathrm{u}_{3} \mathrm{u}_{3}{ }^{*}+\mathrm{u}_{4} \mathrm{u}_{4}{ }^{*}\right)$

$\dot{\mathrm{x}}_{2}=\frac{4 \omega}{\mathrm{r}}\left(\mathrm{u}_{2} \mathrm{u}_{1}^{*}+\mathrm{u}_{1} \mathrm{u}_{2}^{*}-\mathrm{u}_{4} \mathrm{u}_{3}^{*}+\mathrm{u}_{3} \mathrm{u}_{4}^{*}\right)$

$\dot{\mathrm{x}}_{3}=\frac{4 \omega}{\mathrm{r}}\left(\mathrm{u}_{3} \mathrm{u}_{1}{ }^{*}+\mathrm{u}_{4} \mathrm{u}_{2}{ }^{*}+\mathrm{u}_{1} \mathrm{u}_{3}{ }^{*}+\mathrm{u}_{2} \mathrm{u}_{4}{ }^{*}\right)$.

\section{Geo-potential}

To model for the acceleration caused by the Earth's coefficients are taken from WGS84_EGM96 [5]. The forces acting on an artificial satellite due to the Earth's gravity harmonics (zonal, sectorial and tesseral) is modeled using [6], [7] as below,

$\mathrm{V}=\frac{\mathrm{K}^{2}}{\mathrm{r}} \sum_{\mathrm{n}=2}^{\infty}\left(\frac{\mathrm{R}}{\mathrm{r}}\right)^{\mathrm{n}} \sum_{\mathrm{m}=0}^{\mathrm{n}}\left(\mathrm{C}_{\mathrm{nm}} \cos (\mathrm{m} \lambda)+\mathrm{S}_{\mathrm{nm}} \sin (\mathrm{m} \lambda)\right) \mathrm{P}_{\mathrm{nm}} \sin (\phi)$,

where $\mathrm{R}$ is mean equatorial radius of Earth, $\phi$ is the geocentric latitude, $\lambda$ is the longitude, $\mathrm{C}_{\mathrm{nm}}$ and $\mathrm{S}_{\mathrm{nm}}$ are dimensionless constants known as gravity coefficients for zonal, sectorial and tesseral harmonics and $\mathrm{P}_{\mathrm{nm}}$ represent the set of associated Legendre polynomials $[7]$.

\section{Atmospheric drag}

The acceleration vector on a space object due to atmospheric drag $\vec{a}_{\text {aero }}$ is calculated from [7], [8]

$\overrightarrow{\mathrm{a}}_{\mathrm{aero}}=-\frac{1}{2} \rho \mathrm{v}_{\text {rel }}^{2} \mathrm{BC} \frac{\overrightarrow{\mathrm{v}}_{\text {rel }}}{\left|\overrightarrow{\mathrm{v}}_{\text {rel }}\right|}$,

where $\rho$ is the local atmospheric density, $\vec{v}_{\text {rel }}$ is the space objects velocity vector relative to the atmosphere, $v_{\text {rel }}$ is the space object's scalar velocity and BC is the ballistic coefficient. The NRLMSISE00 [9] atmospheric model was used to compute atmospheric densities. 
The velocity vector relative to the rotating atmosphere is given by

$\overrightarrow{\mathrm{v}}_{\mathrm{rel}}=\left[\frac{\mathrm{dx}}{\mathrm{dt}}+\omega_{\oplus} \mathrm{y} \quad \frac{\mathrm{dy}}{\mathrm{dt}}-\omega_{\oplus} \mathrm{x} \frac{\mathrm{dz}}{\mathrm{dt}}\right]^{\mathrm{T}}$

where $\omega_{\oplus}=7.29211 \times 10^{-5} \mathrm{rad} / \mathrm{sec}$ is the rotational rate of Earth.

Usually, $\mathrm{C}=\frac{\mathrm{c}_{\mathrm{DA}}}{\mathrm{M}}$, where $\mathrm{M}$ is the mass of the object, $\mathrm{c}_{\mathrm{D}}$ is the drag coefficient and $A$ is the projected cross-sectional area of the space object perpendicular to the velocity vector.

\section{Solar radiation pressure (SRP)}

The acceleration vector on a space object due to solar radiation pressure $\vec{a}_{\text {srp }}$ is calculated from [10],

$\overrightarrow{\mathrm{a}}_{\text {srp }}=\mathrm{c}_{\mathrm{r}} \frac{\mathrm{A}}{\mathrm{m}} \mathrm{k} \varphi \frac{\overrightarrow{\mathrm{r}}_{\mathrm{sat}}-\overrightarrow{\mathrm{r}}_{\text {sun }}}{\overrightarrow{\mathrm{r}}_{\text {sun }}}$,

where, $c_{r}$ is the constant of reflectivity of the satellite, A is the area of the transverse section of the satellite perpendicular to the disturbing force, $\mathrm{m}$ is the satellite mass, $\mathrm{k}$ is the ratio of the solar constant and the speed of the light, $\varphi$ is the shadow function, which has value ' 1 ', if the satellite is fully illuminated and ' 0 ', if it is in the Earth's shadow, $\overrightarrow{\mathrm{r}}_{\text {sat }}$ is the geocentric vector of the satellite and $\overrightarrow{\mathrm{r}}_{\text {sun }}$ is the the geocentric vector of the Sun.

SIGHT algorithm [7] available in Vallado is used to determine, if the satellite has a direct line of sight with the Sun, and hence whether it is in Earth's shadow. SIGHT algorithm assumes the light from the Sun acts as a point source [7]. Let $\overrightarrow{r_{1}}$ be the geocentric position vector of the satellite and $\overrightarrow{r_{2}}$ be the geocentric position vector of the Sun. The value of $\tau_{\min }$, which minimizes the distance to the central body is given by,

$\tau_{\min }=\frac{\left|\overrightarrow{\mathrm{r}_{1}}\right|^{2}-\overrightarrow{\mathrm{r}_{1}} \cdot \overrightarrow{\mathrm{r}_{2}}}{\left|\overrightarrow{\mathrm{r}_{1}}\right|^{2}+\left|\overrightarrow{\mathrm{r}_{2}}\right|^{2}-2 \overrightarrow{\mathrm{r}_{1}} \cdot \overrightarrow{\mathrm{r}_{2}}}$

A parametric representation of a line between the two position vectors, $\overrightarrow{\mathrm{r}_{1}}$ and $\overrightarrow{\mathrm{r}_{2}}$, is given by

$\left|\vec{c}\left(\tau_{\min }\right)\right|^{2}=\left(1-\tau_{\min }\right)\left|\overrightarrow{r_{1}}\right|^{2}+\left(\overrightarrow{r_{1}} \cdot \overrightarrow{r_{2}}\right) \tau_{\min }$

If $\tau_{\min }<0.0$ or $\tau_{\min }>1.0$, then the satellite is illuminated. ie. if, $\left|\vec{c}\left(\tau_{\min }\right)\right|^{2} \geq 1.0$, then the satellite is illuminated. else, the satellite is not illuminated

If the satellite is illuminated, the perturbation due to solar radiation pressure is computed using Equation (03). If the satellite is not illuminated, the perturbation due to solar radiation pressure is set to zero.

\section{Results and conclusion}

The numerical integration of the above differential equations of motion are carried out with Earth's gravity harmonics, air drag and solar radiation pressure as perturbing forces. The numerical integration of the KS differential equations of motion has been carried out using a fixed step size of fourth order Runge-Kutta method with respect to the initial conditions. The constants used for Earth's equatorial radius $(\mathrm{R})$, and Earth's Gravitational constant $\left(\boldsymbol{k}^{2}\right)$ are $6378.145 \mathrm{~km}$, and $398600.4418 \mathrm{~km}^{3} / \mathrm{s}^{2}$, respectively. In our analysis we assumed, $\mathrm{C}_{\mathrm{D}}=$ 2.2 and $\mathrm{C}_{\mathrm{R}}=1.5$.

As a first step, the artificial satellite Explorer-19, which is at $750 \mathrm{Km}$ height is chosen for the analysis. The initial position and velocity components of satellite are provided in Table 1 [10]. In this study perturbations due to the gravity harmonics terms up to $\mathrm{J}_{4}$, air drag and solar radiation pressure are considered.

Table 1: Initial Condition

\begin{tabular}{|l|c|}
\hline $\mathrm{x}_{1}(\mathrm{~km})$ & 3538.646 \\
\hline $\mathrm{x}_{2}(\mathrm{~km})$ & -2902.799 \\
\hline $\mathrm{x}_{3}(\mathrm{~km})$ & -5483.478 \\
\hline$\dot{x}_{1}(\mathrm{~km} / \mathrm{sec})$ & 5.842408 \\
\hline$\dot{x}_{2}(\mathrm{~km} / \mathrm{sec})$ & -1.772259 \\
\hline$\dot{x}_{3}(\mathrm{~km} / \mathrm{sec})$ & 4.707377 \\
\hline
\end{tabular}

Orbital epoch is 14 Feb 1976 00:00:00 UTC, with area to mass ratio as $13.04 \times 10^{-07} \mathrm{~km}^{2} / \mathrm{kg}$. The accuracy check in the solution at any fictitious time is obtained using the bilinear relation,

$B I=u_{4} u_{1}^{\prime}-u_{3} u_{2}{ }^{\prime}+u_{2} u_{3}{ }^{\prime}-u_{1} u_{4}{ }^{\prime}$

If this $\mathrm{BI}$ is equal to zero, implies the stupendous accuracy in the solution.

The above initial values are used to compute the position and velocity components with respect to various perturbing forces and the accuracy of the solution is determined by computing the bilinear relation. 
Table 2 provides the bilinear relation under the perturbing forces at any time (days). In this Table 2, column 1 contains the time in days, column, 2 contains the approach used for orbit prediction, The $3^{\text {rd }}$ column gives the results generated with gravity alone, $4^{\text {th }}$ column is the results with gravity and drag and without SRP and $5^{\text {th }}$ column includes all the perturbations. The results obtained using the present KS theory is compared with Hany's results ([10]). Comparison shows that the KS results are more accurate than that of Hany's results.

Table 2: Comparison of the Values of Bilinear Relation Corresponding to Their Perturbations Forces

\begin{tabular}{|c|c|c|c|c|}
\hline \multicolumn{5}{|c|}{ The value of bilinear relation (BI) } \\
\hline Time (Days) & Approach & Only gravity & $\begin{array}{l}\text { With pert. and } \\
\text { without SRP }\end{array}$ & $\begin{array}{l}\text { With pert. and } \\
\text { with SRP }\end{array}$ \\
\hline 0.768722 & Hany & $-2.1191 \mathrm{E}-10$ & $-2.4374 \mathrm{E}-10$ & $-2.0372 \mathrm{E}-10$ \\
\hline \multirow{2}{*}{1.537444} & Hany & $-4.1473 \mathrm{E}-10$ & $-4.1745 \mathrm{E}-10$ & $-4.1109 \mathrm{E}-10$ \\
\hline & $\mathrm{KS}$ & $2.9755 \mathrm{E}-10$ & $3.5485 \mathrm{E}-10$ & $3.2546 \mathrm{E}-10$ \\
\hline \multirow{2}{*}{2.306164} & Hany & $-6.0754 \mathrm{E}-10$ & $-6.5119 \mathrm{E}-10$ & $-6.1845 \mathrm{E}-10$ \\
\hline & $\mathrm{KS}$ & 4.3987E-10 & $5.0647 \mathrm{E}-10$ & 4.7337E-10 \\
\hline \multirow{2}{*}{3.843645} & Hany & $-9.8134 \mathrm{E}-10$ & $-1.1559 \mathrm{E}-10$ & $-1.0486 \mathrm{E}-10$ \\
\hline & $\mathrm{KS}$ & $7.6846 \mathrm{E}-10$ & $8.3704 \mathrm{E}-10$ & $7.8162 \mathrm{E}-10$ \\
\hline \multirow{2}{*}{4.612355} & Hany & $-1.1905 \mathrm{E}-09$ & $-1.2632 \mathrm{E}-10$ & $-1.2187 \mathrm{E}-10$ \\
\hline & $\mathrm{KS}$ & $9.3108 \mathrm{E}-10$ & $9.9336 \mathrm{E}-10$ & $9.4341 \mathrm{E}-10$ \\
\hline \multirow{2}{*}{5.381111} & Hany & $-1.3960 \mathrm{E}-09$ & $-1.4697 \mathrm{E}-09$ & $-1.4297 \mathrm{E}-09$ \\
\hline & $\mathrm{KS}$ & $1.0723 \mathrm{E}-09$ & $1.1715 \mathrm{E}-09$ & 1.1095E-09 \\
\hline \multirow{2}{*}{6.14981} & Hany & $-1.6516 \mathrm{E}-09$ & $-1.7016 \mathrm{E}-09$ & $-1.9654 \mathrm{E}-09$ \\
\hline & $\mathrm{KS}$ & $1.2550 \mathrm{E}-09$ & $1.3583 \mathrm{E}-09$ & $1.2766 \mathrm{E}-09$ \\
\hline 6.918555 & Hany & $-1.8762 \mathrm{E}-09$ & -1.9726E-09 & $-1.9654 \mathrm{E}-09$ \\
\hline \multirow{2}{*}{7.687293} & Hany & $-2.0972 \mathrm{E}-09$ & -2.1937E-09 & $-2.1836 \mathrm{E}-09$ \\
\hline & $\mathrm{KS}$ & $1.6060 \mathrm{E}-09$ & $1.7365 \mathrm{E}-09$ & $1.6374 \mathrm{E}-09$ \\
\hline \multirow{2}{*}{69.108767} & Hany & $-1.3006 \mathrm{E}-08$ & -1.2827E-08 & $-1.2816 \mathrm{E}-08$ \\
\hline & $\mathrm{KS}$ & $1.0113 \mathrm{E}-08$ & $1.0696 \mathrm{E}-08$ & $1.0453 \mathrm{E}-08$ \\
\hline \multirow{2}{*}{69.877513} & Hany & $-1.2918 \mathrm{E}-08$ & -1.2700E-08 & $-1.2776 \mathrm{E}-08$ \\
\hline & $\mathrm{KS}$ & $1.0077 \mathrm{E}-08$ & $1.0612 \mathrm{E}-08$ & $1.0370 \mathrm{E}-08$ \\
\hline \multirow{2}{*}{70.646255} & Hany & $-1.2781 \mathrm{E}-08$ & $-1.2550 \mathrm{E}-08$ & $-1.2756 \mathrm{E}-08$ \\
\hline & $\mathrm{KS}$ & $1.0005 \mathrm{E}-08$ & $1.0553 \mathrm{E}-08$ & $1.0318 \mathrm{E}-08$ \\
\hline
\end{tabular}

As a second step, four test cases have been chosen for detailed numerical study with varying eccentricity, whose initial conditions (osculating orbital elements) are given in Table-3.

Table 3: Initial Conditions for Different Test Cases

\begin{tabular}{|c|c|c|c|c|}
\hline Variables & Case A & Case B & Case $\mathrm{C}$ & Case D \\
\hline Semi major Axis (a) (km) & 46478.6 & 46478.6 & 46478.6 & 46478.6 \\
\hline Eccentricity (e) & 0.001 & 0.5 & 0.6 & 0.7 \\
\hline Inclination (i) (deg) & 51.6 & 51.6 & 51.6 & 51.6 \\
\hline Arg. of Perigee $(\boldsymbol{\omega})(\mathrm{deg})$ & 25.24 & 25.24 & 25.24 & 25.24 \\
\hline True Anomaly (f) (deg) & 311.234 & 311.234 & 311.234 & 311.234 \\
\hline Mean Anomaly (deg) & 311.32 & 344.703 & 349.282 & 353.178 \\
\hline Apogee $(\mathrm{km})$ & 40146.942 & 63339.76 & 67987.62 & 72635.48 \\
\hline Perigee $(\mathrm{km})$ & 40053.984 & 16861.16 & 12213.3 & 7565.443 \\
\hline
\end{tabular}

The Earth's gravity harmonics terms up to $\mathrm{J}_{6,6}$, air drag and solar radiation pressure are included as the perturbing forces in the equations of motion. Orbital epoch considered is 02 June 2015 00:00:00 UTC, with area to mass ratio as $10.454 \mathrm{x} 10^{-03} \mathrm{~km}^{2} / \mathrm{kg}$.

The initial conditions provided in Table 3 are used for orbit propagation. Osculating orbital elements obtained for 30 days duration with a step size of 1degree using the present KS theory is compared with High Precision Orbit propagator (HPOP). High Precision Orbit propagator uses numerical integration of the differential equations of motion to generate ephemeris. HPOP, available in STK 9.2 is used for comparing the results with the present KS theory.

Table 4 to 7 gives the comparison between KS and HPOP values of orbital elements (osculating elements) for 30 days. In these tables, column 1 contains the time in days, column 2 contains the approach used for orbit prediction, columns 3 to 9 contain the information regarding osculating orbital elements semi-major axis (a), eccentricity (e), orbital inclination (i), right ascension of ascending node ( $\Omega$ ), argument of perigee $(\omega)$ plus mean anomaly $(\mathrm{M})$, apogee altitude $(\mathrm{Ha})$ and perigee altitude $(\mathrm{Hp})$. From these tables, it is clear that the results obtained from the present KS regular equations match very well with HPOP results.

Table 4: Comparison Between KS and HPOP Values of Orbital Elements (Case A)

\begin{tabular}{|c|c|c|c|c|c|c|c|c|}
\hline Days & Approach & $a(\mathrm{~km})$ & e & i (deg) & $\Omega($ deg) & $\begin{array}{c}\omega+M \\
\text { (deg) }\end{array}$ & $\mathrm{Ha}(\mathrm{km})$ & $\mathrm{Hp}(\mathrm{km})$ \\
\hline \multirow{2}{*}{1} & HPOP & 46477.2938 & 0.000989 & 51.5990 & 349.2070 & 288.4800 & 40145.1180 & 40053.1956 \\
\hline & KS & 46477.3006 & 0.000989 & 51.5994 & 349.2072 & 288.4793 & 40145.1070 & 40053.2202 \\
\hline \multirow[b]{2}{*}{5} & HPOP & \begin{tabular}{|l}
46477.0159 \\
\end{tabular} & 0.000970 & 51.5990 & 349.1840 & 96.1570 & 40143.9701 & 40053.7877 \\
\hline & ks & \begin{tabular}{|l|}
46477.0127 \\
\end{tabular} & 0.000969 & 51.5993 & 349.1837 & 96.1567 & 40143.9286 & 40053.8229 \\
\hline \multirow{2}{*}{10} & HPOP & \begin{tabular}{|l|}
46478.2539 \\
\end{tabular} & 0.000945 & 51.6000 & 349.1550 & 215.7530 & 40144.0239 & 40056.2099 \\
\hline & KS & \begin{tabular}{|l|}
46478.2674 \\
\end{tabular} & 0.000941 & 51.5999 & 349.1547 & 215.7540 & 40143.8881 & 40056.3727 \\
\hline \multirow[b]{2}{*}{15} & HPOP & \begin{tabular}{|l|}
46478.5823 \\
\end{tabular} & 0.000932 & 51.6000 & 349.1250 & 335.3480 & 40143.7663 & 40057.1243 \\
\hline & KS & \begin{tabular}{|l|}
46478.5863 \\
\end{tabular} & 0.000926 & 51.6000 & 349.1241 & 335.3486 & 40143.4966 & 40057.4020 \\
\hline \multirow[b]{2}{*}{20} & HPOP & \begin{tabular}{|l|}
46476.9937 \\
\end{tabular} & 0.000899 & 51.5990 & 349.0950 & 94.9440 & 40140.6571 & 40057.0563 \\
\hline & KS & \begin{tabular}{|l|}
46476.9983 \\
\end{tabular} & 0.000891 & 51.5993 & 349.0948 & 94.9456 & 40140.2507 & 40057.4720 \\
\hline \multirow[b]{2}{*}{25} & HPOP & \begin{tabular}{|l|}
46478.2936 \\
\end{tabular} & 0.000871 & 51.6000 & 349.0660 & 214.5410 & 40140.6485 & 40059.6647 \\
\hline & ks & \begin{tabular}{|l|}
46478.2876 \\
\end{tabular} & 0.000860 & 51.5999 & 349.0658 & 214.5431 & 40140.1088 & 40060.1924 \\
\hline \multirow[b]{2}{*}{30} & HPOP & \begin{tabular}{|l|}
46478.5498 \\
\end{tabular} & 0.000856 & 51.6000 & 349.0360 & 334.1350 & 40140.2041 & 40060.6215 \\
\hline & KS & 46478.5245 & 0.000844 & 51.6000 & 349.0352 & 334.1385 & 40139.6181 & 40061.1570 \\
\hline
\end{tabular}


Table 5: Comparison Between KS and HPOP Values of Orbital Elements (Case B)

\begin{tabular}{|c|c|c|c|c|c|c|c|c|}
\hline Days & Approach & $\mathrm{a}(\mathrm{km})$ & $\mathrm{e}$ & $\mathrm{i}(\mathrm{deg})$ & $\Omega(\mathrm{deg})$ & $\begin{array}{c}\omega+\mathrm{M} \\
(\mathrm{deg})\end{array}$ & $\mathrm{Ha}(\mathrm{km})$ & $\mathrm{Hp}(\mathrm{km})$ \\
\hline \multirow{2}{*}{1} & HPOP & 46474.3036 & 0.499972 & 51.5980 & 349.2040 & 321.8950 & 63332.0053 & 16860.3278 \\
\cline { 2 - 9 } & $\mathrm{KS}$ & 46474.2650 & 0.499971 & 51.5985 & 349.2041 & 321.8958 & 63331.9117 & 16860.3442 \\
\hline \multirow{2}{*}{5} & HPOP & 46475.3509 & 0.499948 & 51.5990 & 349.1570 & 129.7060 & 63332.4777 & 16861.9501 \\
\cline { 2 - 9 } & $\mathrm{KS}$ & 46475.3026 & 0.499947 & 51.5990 & 349.1569 & 129.7104 & 63332.3366 & 16861.9945 \\
\hline \multirow{2}{*}{10} & HPOP & 46475.0006 & 0.499934 & 51.5980 & 349.1080 & 249.4640 & 63331.2750 & 16862.4523 \\
\cline { 2 - 9 } & KS & 46474.9532 & 0.499930 & 51.5982 & 349.1077 & 249.4722 & 63331.0527 & 16862.5796 \\
\hline \multirow{2}{*}{15} & HPOP & 46478.2470 & 0.499937 & 51.5990 & 349.0550 & 369.2220 & 63336.3059 & 16863.9142 \\
\cline { 2 - 9 } & KS & 46478.2936 & 0.499932 & 51.5987 & 349.0542 & 369.2339 & 63336.1613 & 16864.1519 \\
\hline \multirow{2}{*}{20} & HPOP & 46475.3205 & 0.499887 & 51.5980 & 348.9990 & 128.9860 & 63329.5692 & 16864.7977 \\
\cline { 2 - 9 } & KS & 46475.2428 & 0.499879 & 51.5978 & 348.9981 & 129.0026 & 63329.0827 & 16865.1290 \\
\hline \multirow{2}{*}{25} & HPOP & 46475.0065 & 0.499870 & 51.5970 & 348.9500 & 248.7430 & 63328.3118 & 16865.4272 \\
\cline { 2 - 8 } & KS & 46474.9625 & 0.499860 & 51.5971 & 348.9491 & 248.7658 & 63327.8056 & 16865.8453 \\
\hline \multirow{2}{*}{30} & HPOP & 46477.9257 & 0.499867 & 51.5970 & 348.8960 & 368.5010 & 63332.5850 & 16866.9924 \\
\cline { 2 - 8 } & KS & 46478.0107 & 0.499859 & 51.5977 & 348.8957 & 368.5281 & 63332.3078 & 16867.4396 \\
\hline
\end{tabular}

Table 6: Comparison Between KS and HPOP Values of Orbital elements (Case C)

\begin{tabular}{|c|c|c|c|c|c|c|c|c|}
\hline Days & Approach & $\mathrm{a}(\mathrm{km})$ & $\mathrm{e}$ & $\mathrm{i}(\mathrm{deg})$ & $\Omega$ (deg) & $\omega+\mathrm{M}(\mathrm{deg})$ & $\mathrm{Ha}(\mathrm{km})$ & $\mathrm{Hp}(\mathrm{km})$ \\
\hline \multirow{2}{*}{1} & HPOP & 46471.2600 & 0.599956 & 51.5980 & 349.2010 & 326.5090 & 67973.8371 & 12212.4086 \\
\cline { 2 - 9 } & KS & 46471.1700 & 0.599955 & 51.5979 & 349.2011 & 326.5106 & 67973.6287 & 12212.4275 \\
\hline \multirow{2}{*}{5} & HPOP & 46472.1300 & 0.599932 & 51.5980 & 349.1360 & 134.4610 & 67974.1026 & 12213.8743 \\
\cline { 2 - 9 } & KS & 46472.0200 & 0.599930 & 51.5984 & 349.1356 & 134.4687 & 67973.8452 & 12213.9208 \\
\hline \multirow{2}{*}{10} & HPOP & 46471.8600 & 0.599919 & 51.5980 & 349.0690 & 254.3900 & 67973.0708 & 12214.3715 \\
\cline { 2 - 9 } & KS & 46471.7400 & 0.599915 & 51.5975 & 349.0683 & 254.4061 & 67972.7242 & 12214.4896 \\
\hline \multirow{2}{*}{15} & HPOP & 46478.2000 & 0.599942 & 51.5980 & 348.9950 & 374.3200 & 67984.2874 & 12215.8322 \\
\cline { 2 - 9 } & KS & 46478.2700 & 0.599938 & 51.5983 & 348.9950 & 374.3440 & 67984.2271 & 12216.0474 \\
\hline \multirow{2}{*}{20} & HPOP & 46472.0900 & 0.599875 & 51.5970 & 348.9180 & 134.2600 & 67971.4096 & 12216.5058 \\
\cline { 2 - 9 } & KS & 46471.9600 & 0.599867 & 51.5969 & 348.9177 & 134.2919 & 67970.8281 & 12216.8204 \\
\hline \multirow{2}{*}{25} & HPOP & 46471.8600 & 0.599860 & 51.5960 & 348.8510 & 254.1890 & 67970.3410 & 12217.1092 \\
\cline { 2 - 8 } & KS & 46471.7500 & 0.599851 & 51.5960 & 348.8504 & 254.2308 & 67969.7396 & 12217.4952 \\
\hline \multirow{2}{*}{30} & HPOP & 46477.8500 & 0.599878 & 51.5970 & 348.7780 & 374.1190 & 67980.7481 & 12218.6680 \\
\cline { 2 - 8 } & KS & 46478.0200 & 0.599871 & 51.5970 & 348.7773 & 374.1694 & 67980.6867 & 12219.0816 \\
\hline
\end{tabular}

Table 7: Comparison Between KS and HPOP Values of Orbital Elements (Case D)

\begin{tabular}{|c|c|c|c|c|c|c|c|c|}
\hline Days & Approach & $\mathrm{a}(\mathrm{km})$ & $\mathrm{e}$ & $\mathrm{i}(\mathrm{deg})$ & $\Omega(\mathrm{deg})$ & $\begin{array}{c}\omega+\mathrm{M} \\
(\mathrm{deg})\end{array}$ & Ha $(\mathrm{km})$ & Hp $(\mathrm{km})$ \\
\hline \multirow{2}{*}{1} & HPOP & 46462.7958 & 0.699919 & 51.5970 & 349.1950 & 330.4980 & 72604.8708 & 7564.4469 \\
\cline { 2 - 8 } & KS & 46462.5248 & 0.699917 & 51.5968 & 349.1947 & 330.5023 & 72604.3089 & 7564.4667 \\
\hline \multirow{2}{*}{5} & HPOP & 46463.3951 & 0.699897 & 51.5970 & 349.0910 & 138.8280 & 72604.8369 & 7565.6793 \\
\cline { 2 - 8 } & KS & 46463.1153 & 0.699894 & 51.5973 & 349.0906 & 138.8461 & 72604.2307 & 7565.7259 \\
\hline \multirow{2}{*}{10} & HPOP & 46463.1981 & 0.699885 & 51.5960 & 348.9850 & 259.2220 & 72603.9530 & 7566.1692 \\
\cline { 2 - 8 } & KS & 46462.893 & 0.699881 & 51.5962 & 348.9849 & 259.2584 & 72603.2366 & 7566.2754 \\
\hline \multirow{2}{*}{15} & HPOP & 46483.3502 & 0.699984 & 51.5980 & 348.8700 & 379.6180 & 72642.8093 & 7567.6171 \\
\cline { 2 - 8 } & KS & 46483.6881 & 0.699982 & 51.5982 & 348.8698 & 379.6727 & 72643.3046 & 7567.7975 \\
\hline \multirow{2}{*}{20} & HPOP & 46463.3612 & 0.699846 & 51.5950 & 348.7480 & 140.0280 & 72602.4284 & 7568.0200 \\
\cline { 2 - 8 } & KS & 46463.0497 & 0.699838 & 51.5953 & 348.7477 & 140.1022 & 72601.5112 & 7568.3141 \\
\hline \multirow{2}{*}{25} & HPOP & 46463.2053 & 0.699833 & 51.5940 & 348.6430 & 260.4220 & 72601.5387 & 7568.5979 \\
\cline { 2 - 8 } & KS & 46462.9154 & 0.699823 & 51.5943 & 348.6421 & 260.5161 & 72600.6028 & 7568.9541 \\
\hline \multirow{2}{*}{30} & HPOP & 46488.0426 & 0.699962 & 51.5960 & 348.5280 & 380.8190 & 72649.7865 & 7570.0247 \\
\cline { 2 - 8 } & KS & 46488.8807 & 0.699960 & 51.5968 & 348.5270 & 380.9316 & 72651.1039 & 7570.3834 \\
\hline \multirow{2}{*}{} & & & & & & & &
\end{tabular}

The following figures 1 to 12, shows the differences between the KS and HPOP values of the important orbital parameters semi-major axis, eccentricity and inclination, which define size, shape and orientation of the orbit for Cases A, B, C and D.

\section{CASE A}

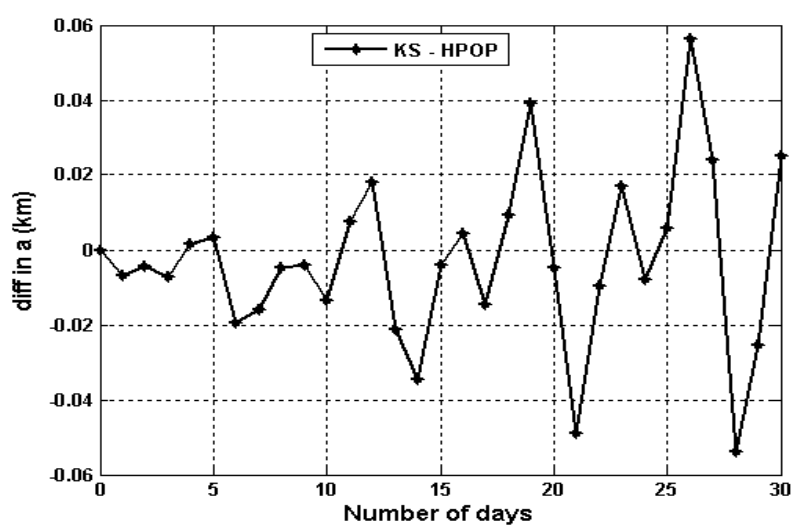

Fig. 1: Difference Between KS and HPOP in Semi-Major Axis. 


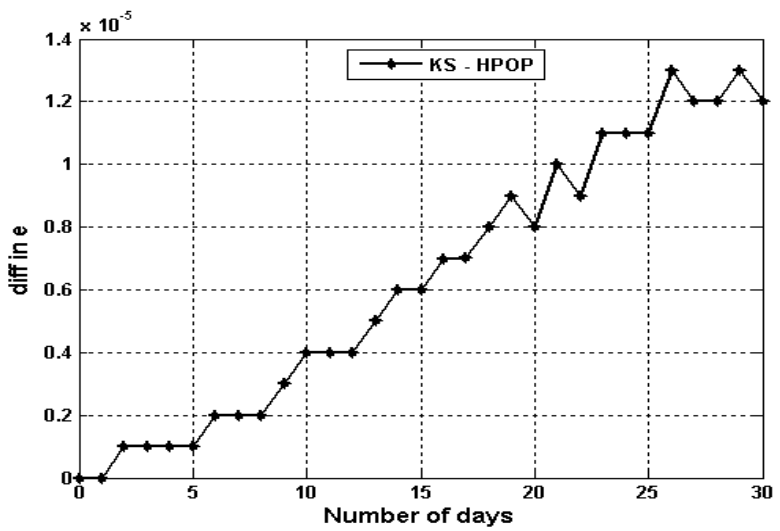

Fig. 2: Difference Between KS and HPOP in Eccentricity.

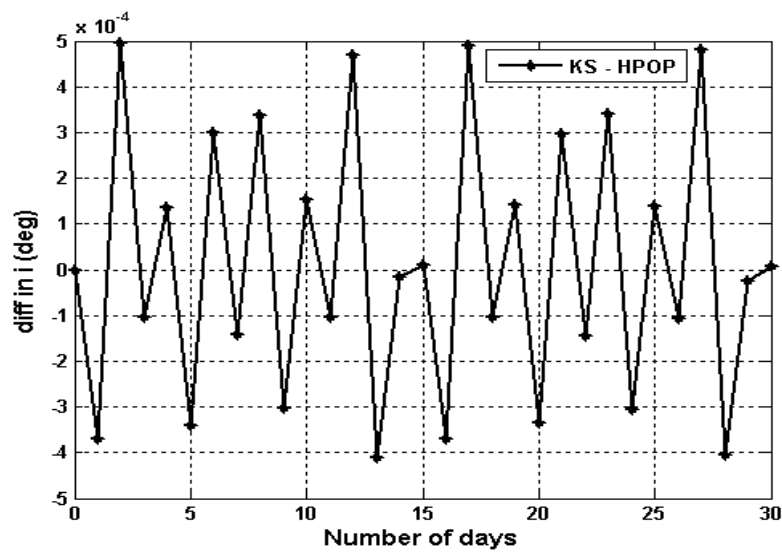

Fig. 3: Difference Between KS and HPOP in Inclination.

\section{CASE B}

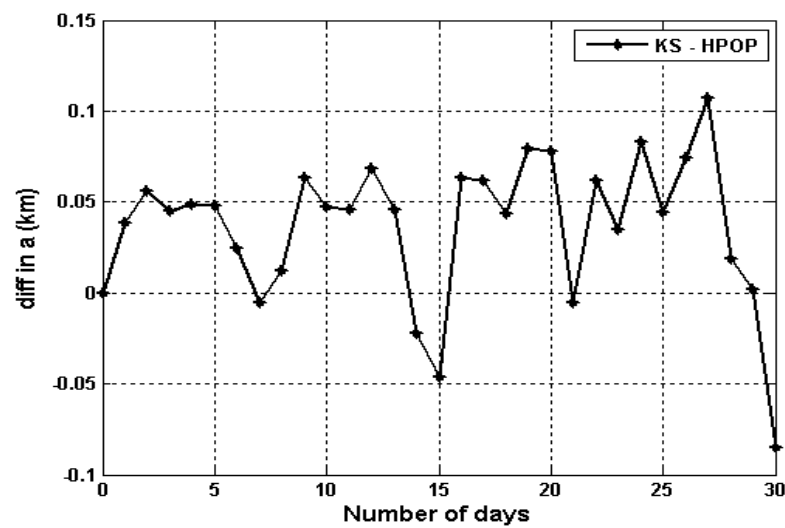

Fig. 4: Difference Between KS and HPOP in Semi-Major Axis.

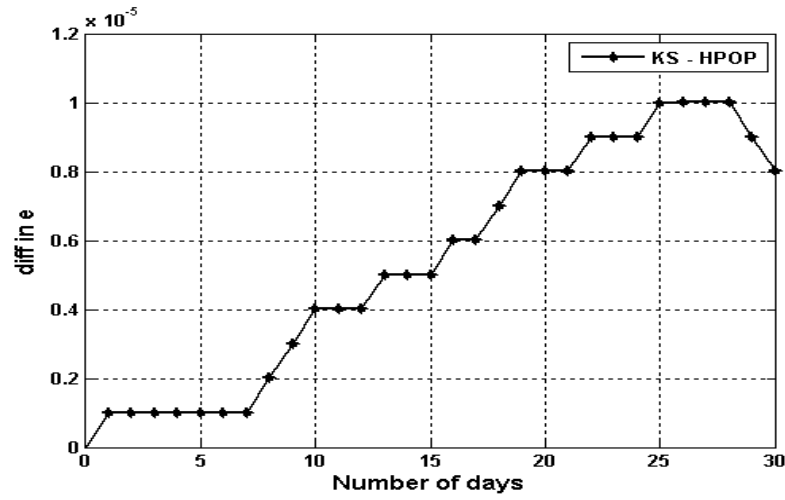

Fig. 5: Difference between KS and HPOP in Eccentricity. 


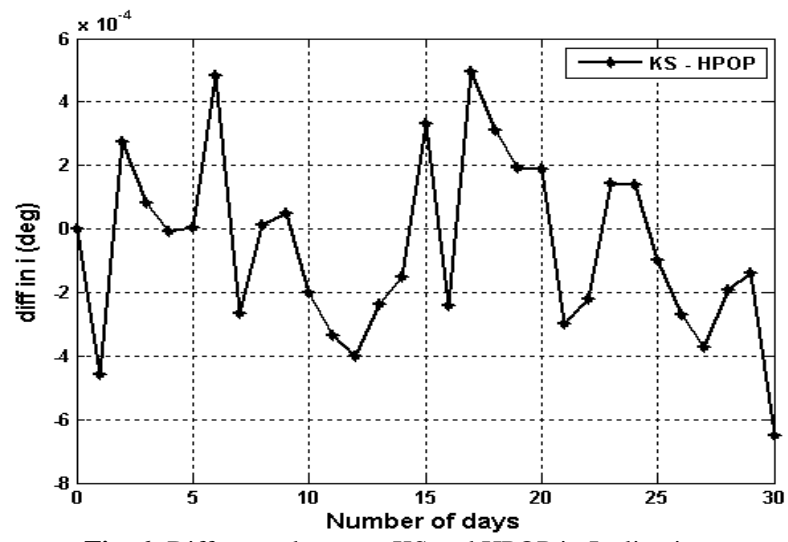

Fig. 6: Difference between KS and HPOP in Inclination.

\section{CASE C}

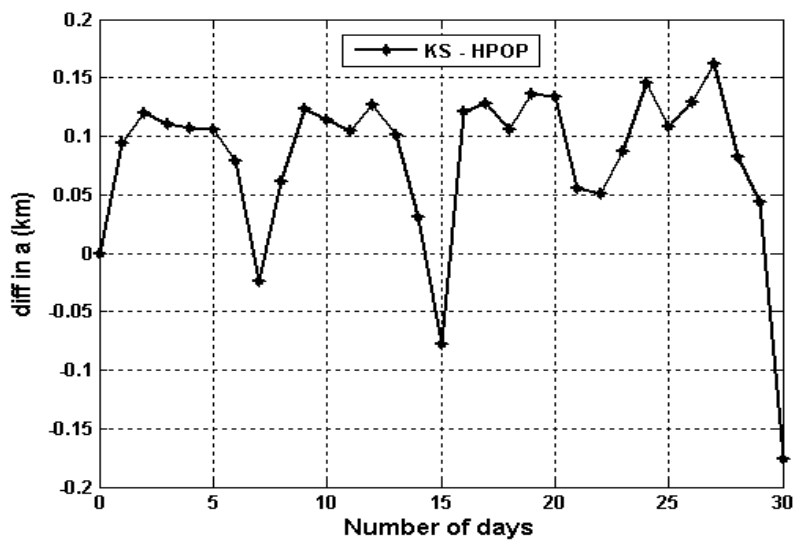

Fig. 7: Difference Between KS and HPOP in Semi-Major Axis.

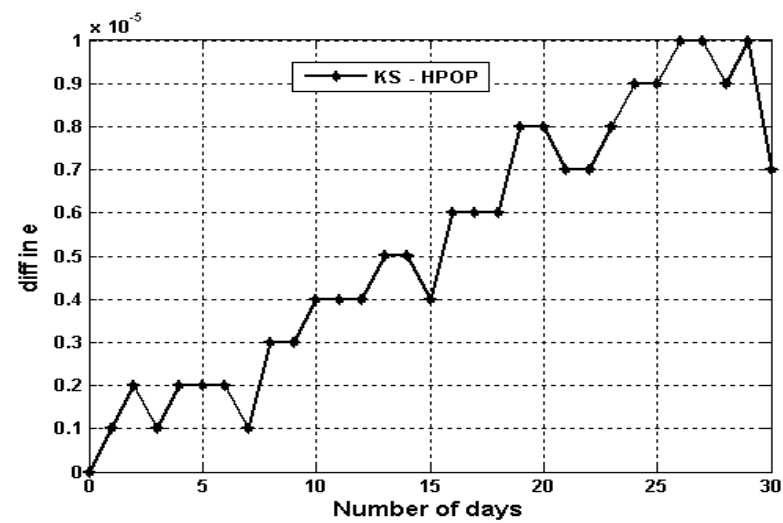

Fig. 8: Difference Between KS and HPOP in Eccentricity.

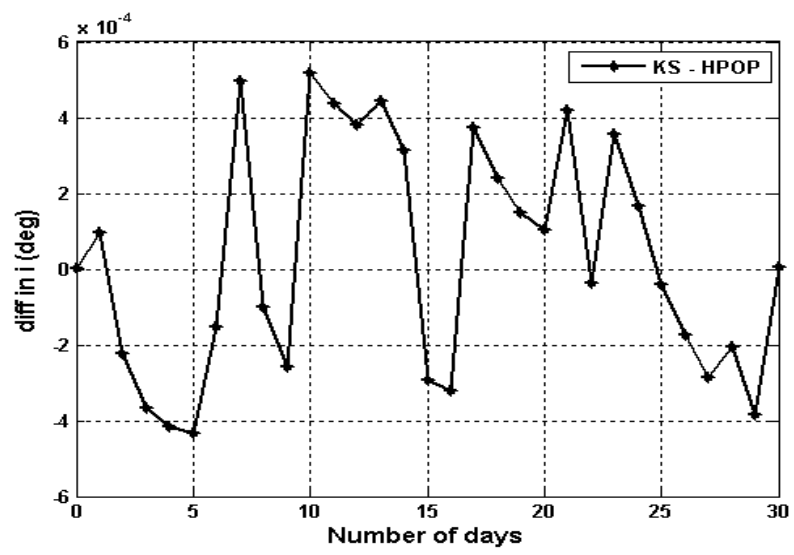

Fig. 9: Difference between KS and HPOP in Inclination. 


\section{CASE D}

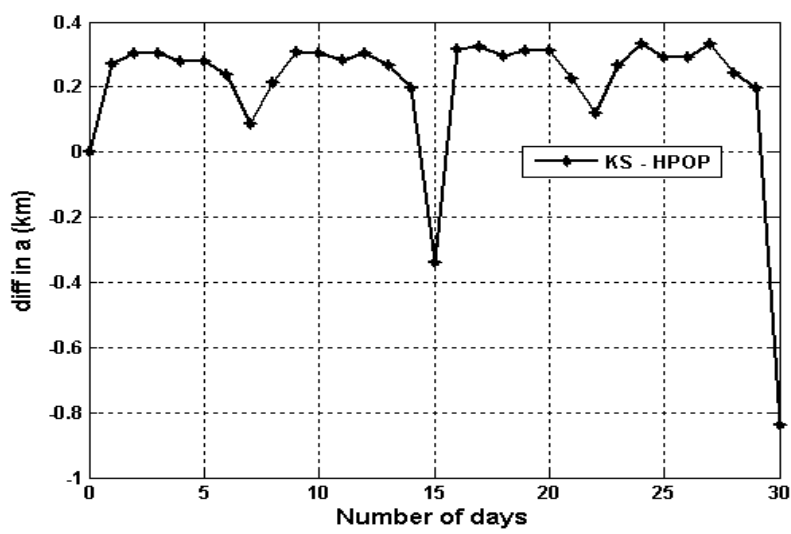

Fig. 10: Difference between KS and HPOP in Semi-Major Axis.

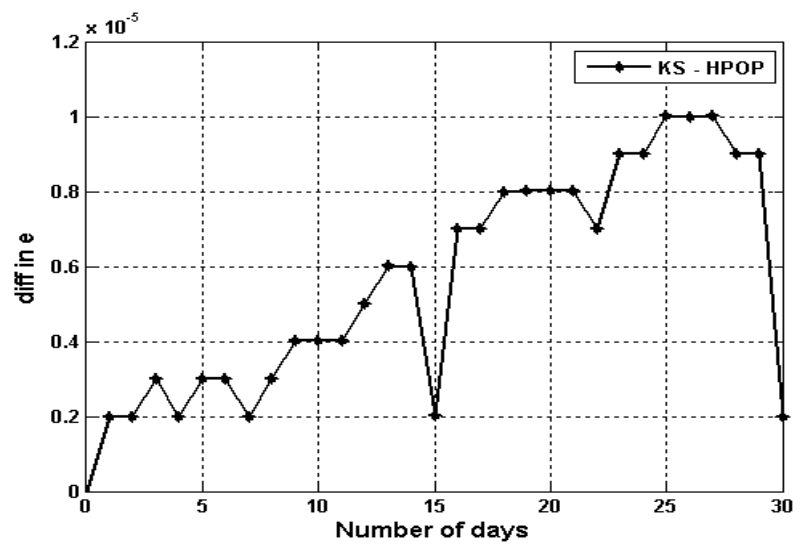

Fig. 11: Difference between KS and HPOP in Eccentricity.

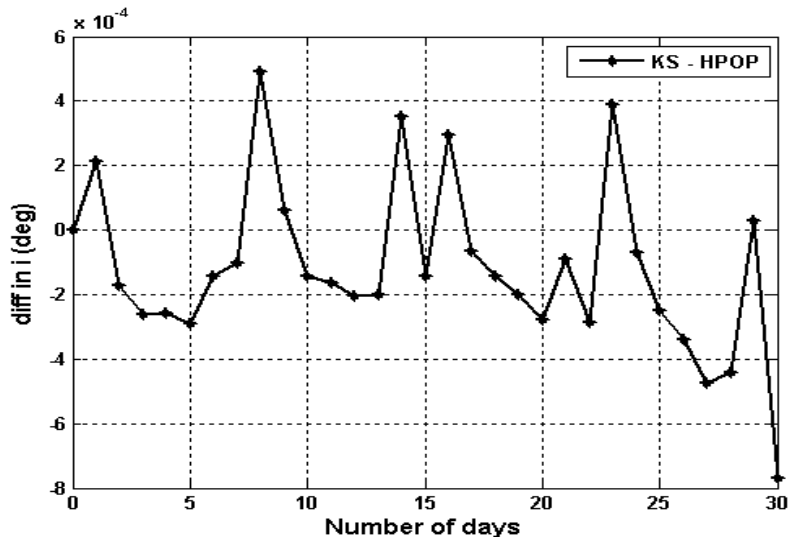

Fig. 12: Difference between KS and HPOP in Inclination.

Among all the test cases, the maximum difference between KS and HPOP theories absolute values of for 30 days in semi-major axis, eccentricity and inclination are found to be $0.838 \mathrm{~km}, 0.000015$ and $0.000872 \mathrm{deg}$, respectively. Hence, from these all figures also, it is evident that the results obtained from KS theory are very well compared with HPOP results. The comparison shows that the KS method provides one of the best techniques for orbit prediction

\section{References}

[1] P.Kustaanheimo and E.L.Stiefel, "Perturbation Theory of Kepler Motion Based on Spinor regularization” J Reine Angew Math $218: 204-19$, 1965.

[2] E.L.Stiefel.G.Scheifele, "Linear and Regular celestial Mechanics", New York, Springer-Verlag, 1971.

[3] Graf, Jr. O.F., Mueller, A., and Starke, S., "The Method of Averages Applied to the KS Differential Equations", NASA-CR-151607, (1977).

[4] T.R.Saritha Kumari and M.Xavier James Raj, "Orbit Predictions using KS element equations with Earth's Oblateness", Journal of Aerospace Sciences and Technologies, ISSN 0972-950X, V.68, No.1, pp.1-7, Paper code: V68 N1/947-2017.

[5] Lemoine, F. G., S. C. Kenyon, J. K. Factor, R.G. Trimmer, N. K. Pavlis, D. S. Chinn, C. M. Cox, S. M. Klosko, S. B. Luthcke, M. H. Torrence, Y. M. Wang, R. G. Williamson, E. C. Pavlis, R. H. Rapp and T. R. Olson (1998). The Development of the Joint NASA GSFC and the National Imagery and Mapping Agency (NIMA) Geopotential Model EGM96. NASA/TP-1998-206861, July 1998.

[6] Chobotov, Vladimir; Przemieniecki, J S , "Orbital mechanics", AIAA, 1996.

[7] Valledo, David A, "Fundamentals of Astrodynamics and applications", Kluwer Academic Publishers, 2001.

[8] Escobal, Pedro Ramon., "Methods of orbit determination", New York, John Wiley, 1965.

[9] NRL NRLMSISE-00 website.

[10] Hany R. Dwidar ,"Prediction of Satellite Motion under the Effects of the Earth's Gravity, Drag force and Solar Radiation Pressure in terms of the KS-regularized variables", IJACSA,Vol.5, No. 5, 2014. 